\title{
O decurso da critica marxista e a relevância das acepções lukacsianas
}

Francigelda Ribeiro ${ }^{1}$

RESUMO: Este artigo apresenta uma discussão acerca da crítica literária de tradição marxista, ressaltando sua origem e desenvolvimento, sobretudo, destacando as contribuições do húngaro Georg Lukács, bem como abordando a contribuição de alguns expoentes para a atualização de tal legado.

ABSTRACT: This paper presents a discussion on the literary criticism of the Marxist tradition, highlighting its origin and development, particularly by emphasizing the contributions of the Hungarian Georg Lukacs, as well as broaching the contribution of some exponents to update this legacy.

PALAVRAS-CHAVE: Crítica literária marxista; Realismo crítico; Georg Lukács KEYWORDS: Marxist literary criticism; Critical realism; Georg Lukacs

\section{Arte e seu alcance social}

A relação entre arte e sociedade envolve controvérsias que, ao longo dos anos, têm colaborado para a atualização e a amplitude dos princípios teóricos que validam a pesquisa do conteúdo social das obras artísticas. No que tange, especificamente, à estética de orientação marxista, posições diversas se processam no intento de expressar tal relação de forma mais adequada, assim novas possibilidades investigativas são sempre engendradas. Malgrado os inflacionários questionamentos surgidos acerca da validade dos postulados de Marx diante da quase inexistência da práxis socialista desde os últimos anos do século XX, há de se destacar o constante trabalho de pesquisadores no sentido de revisitá-los, incluindo as abordagens de caráter estético. 
As primeiras perquirições da arte em sua relação com as demais esferas da atividade humana não foram primazia nem exclusividade da intelligentsia marxista. O cerne da polêmica envolve as concepções idealistas ou materialistas do fenômeno estético e remonta ao tour de force dos filósofos da Grécia clássica ${ }^{2}$. Todavia, somente com a institucionalização da crítica literária - que, no século XIX, ultrapassou os aspectos biográficos e impressionistas, chegando ao século $\mathrm{XX}$ gestada por correntes tais como formalismo, new criticism, estruturalismo, sociologia da literatura, estética da recepção, dentre outras - foi possivel a sistematização do debate, que veio a incorrer no paralelismo estabelecido entre as correntes que defendem a arte como um fim em si mesma, tendências que se arrogam cientificidade, e as que negam a total autonomia da literatura em relação às questões extratextuais, conferindo-lhe um condicionamento social.

O manual Teoria da literatura e metodologia dos estudos literários, de René Wellek e Austin Warren, de 1942, - destacado, aqui, pela influência no debate literário em diversos países - propõe um método dual para o estudo da literatura: a abordagem extrínseca e o estudo intrínseco. Dualismos assim são peremptoriamente arguidos por Antonio Candido no livro Literatura e sociedade, de 1965. Na tentativa de obliterar essa dicotomia, Candido advoga que uma crítica só se fará integralmente, caso haja a fusão do texto e do contexto, em uma perspectiva dialética, reivindicando que a interpretação estética deve assimilar a dimensão social como fator intrínseco à economia da obra.

Candido lembra que não foi a orientação sociológica que sucumbiu em meio à crítica moderna, visto que tal orientação será sempre legítima, mas o sociologismo - tendência na qual a obra literária é destituída de sua especificidade estética, passando a ser explicada, estritamente, por meio de elementos extrínsecos. Para o crítico, o

\footnotetext{
2 "Em suma, enquanto Platão se preocupa com a subjetividade criadora, com o 'gênio poético', Aristóteles se volta para a estrutura objetiva da arte e para as suas determinações sociais. Esta diversidade corresponde, ou antes decorre, da diversa orientação filosófica (idealista ou materialista) [...] dos dois pensadores" (COUTINHO, 1967, p. 93).
} 
elemento social, assim como os demais (linguísticos, psicológicos etc.), deve ser tomado na condição de componente estrutural, segundo a função que exerce no nível de feitura da obra. Certas correntes, no entanto, arrogam-se justificar a arte pelo que ela tem de significado imanente, em atitude de menosprezo à sua dimensão histórica, expediente que, segundo Candido, "o pensamento contemporâneo não enfrenta de maneira adequada os problemas que o preocupam" (CANDIDO, 2000, p. 15).

A partir das categorias defendidas pelas correntes ditas imanentistas, adveio o conceito de organicidade da obra, cuja concepção permitiu - de modo contrário ao que aparentou - variar os diversos fatores que condicionam o objeto literário, interpretando-os enquanto elemento da sua estrutura, conforme predica Candido. Assim, cada um dos elementos, tomados como parte essencial do todo orgânico, passaram a ser concebidos, legitimamente, como essenciais, inclusive os histórico-sociais. Objetivando focalizar esses elementos, filtrados à economia interna da obra, o crítico evidencia que o simplismo, com que sociólogos e psicólogos julgaram explicar a totalidade do fenômeno artístico com recursos exclusivos de suas disciplinas, legou consequências duvidosas ao método por eles adotado. Desde o século XIX, "este gênero de estudo tem permanecido insatisfatório, ou ao menos incompleto, devido à falta de um sistema coerente de referências" (CANDIDO, 2000, p. 17).

Essa ausência de delimitação no método de análise tem sido, inclusive, extensamente abordada por vários pesquisadores preocupados com a perspectiva social da arte. O pesquisador francês Robert Escarpit (1918-2000), no ensaio Sociologie de la littérature, editado em 1958, anteriormente a Candido, já questionava a fragilidade dessa área de pesquisa, no que diz respeito ao método.

A ausência de uma verdadeira perspectiva sociológica é visivel mesmo nos melhores manuais da história literária do tipo tradicional. Acontece que, por vezes, os autores têm consciência de uma dimensão social e tentam dar dela uma representação, mas à falta de um método rigoroso e adaptado a esse fim ficam na maior parte das 
vezes prisioneiros do esquema tradicional do homem e da obra. As profundezas da história perdem-se assim como num écran a duas dimensões e o artefato literário sofre com isso distorções comparáveis às de um mapa-múndi numa projeção plana. [...] Mesmo se uma representação perfeita for possivel, o essencial é que, biógrafos ou comentadores, historiadores ou críticos, os estudiosos da literatura tenham do facto literário - presente ou passado - uma visão completa e não deformada (ESCARPIT, 1969, p. 10-11).

Tal reclamação aparece, ademais, nos ensaios Os marxistas e a arte (1967) e Sociologia da literatura (1971), respectivamente, de Leandro Konder e Giovanni Ricciard. A primeira pesquisa sistematizada com o objetivo de fixar as relações entre literatura e sociedade, segundo os pesquisadores supracitados, é atribuída a Madame de Staël (17661817). O seu ensaio De la littérature considérée dans ses rapports avec les institutions sociales (1842) constitui, antes de tudo, "um livro que procura definir a função social da literatura e que, por isso, contém um certo número de intuições metodológicas muito novas" (DENIS, 2002, p. 158). Segundo Escarpit - com o progresso cultural e técnico, que impulsionou o desenvolvimento da indústria do livro - "a literatura começa a tomar consciência da sua dimensão social” (ESCARPIT, 1969, p. 13). Acrescenta, ainda, que, publicada nesse contexto, a obra de Madame de Staël compila as noções da literatura como parte do contexto social. Devendo-se, ressaltar, conforme indica Ricciard, que outras investidas orientadas no mesmo sentido foram empreendidas anteriormente à Staël, todavia sem acuidade metodológica. O marxista norte-americano Fredric Jameson, em seu Marxismo e forma, de 1971, faz uma ressalva no que diz respeito aos primórdios da sociologia da literatura, esclarecendo que a obra de Staël "só pode ser considerada, depois de Vico e Montesquieu, o primeiro tratado de fôlego sobre o assunto" (JAMESON, 1985, p. 13).

$\mathrm{Na}$ esteira de Escarpit, tanto Candido quanto Ricciard destacam a doutrina de Hyppolite Taine (1828-1893) como a segunda tentativa sistemática de estabelecer os liames entre arte e sociedade. Pelo esquema ternário: raça, meio, momento, Taine tentou determinar o 
fenômeno literário como reflexo de tal esquema, avaliando em que medida ele correspondia à realidade. Tomando, assim, a obra de arte como documento histórico, concebeu-a a partir dos hábitos da época que a engendram. Conforme Escarpit, faltaram a Taine métodos que se acomodassem à especificidade do artefato literário para além das ciências da natureza.

Após citar outros pesquisadores de destaque, tais como Émile Zola (1840-1902) e Jean-Marie Guyau (1854-1888), Ricciard predica que se deve a Karl Marx (1818-1883) uma visão global estruturante acerca das relações entre arte e sociedade. Em consonância com o materialismo histórico, Marx ressalta a gênese social da obra de arte, sem, com isso, condicioná-la exclusivamente aos elementos externos, reconhecendo seu substrato estético. Todavia, "os primeiros teóricos marxistas mostraram-se bastante discretos a respeito das questões literárias" (ESCARPIT, 1969, p. 15-16). Somente a partir do século XX, com o marxista russo Plekhanov, é que uma teoria marxista da literatura foi elaborada, embora submersa em vasto sociologismo.

\section{Estética marxista: tradição e atualidade}

No ensaio Os marxistas e a arte (1967), Leandro Konder alerta que, no que tange à estética marxista, o sociologismo foi sempre o mais substancial obstáculo ao seu plano teórico. Konder inicia seu excurso fazendo alusão ao historiador e filósofo Karl Kautsky (1854-1938) ressaltando-lhe o modo circunstancial com que tratou as questões relacionadas à estética, elucidando que sua preocupação voltou-se tão somente para o valor histórico-documental da arte, ou seja, para a sua gênese social, relegando-lhe o valor estético. Focaliza, ainda, nesses primeiros intentos de sistematização de uma estética marxista, o pensamento do russo Georgi Plekhanov (1856-1918) autor de A arte e a vida social, que se destaca como o "verdadeiro criador da teoria estética do marxismo" (KONDER, 1967, p. 39); no entanto, seus esforços coligiram-se na defesa do critério da subserviência da arte à experiência 
social. Sua tarefa básica visou a "determinar o 'equivalente social' da obra analisada, isto é, o conteúdo e a psicologia social e classista que ela expressa" (COUTINHO, 1967, p. 99). Nesse sentido, Adolfo Sánchez Vázquez (1978, p. 14) reforça que há em Plekhanov uma "tendência no sentido de reduzir a estética marxista a uma sociologia da arte".

Nessa revisão bibliográfica, Konder elucida que Franz Mehring (1846-1919) atuou no sentido de combater o sectarismo e o imediatismo aos quais estavam sendo submetidos os valores estéticos que, não só isoladamente em Plekhanov, mas também entre os intelectuais marxistas no período da Segunda Internacional (1889-1914), haviam se tornado tendência comum. Mehring, por todo o conhecimento que detinha acerca da literatura clássica, estava convicto de que "a autêntica obra de arte é mais do que um mero documento sobre o seu tempo ou sobre a sua circunstância social" (KONDER, 1967, p. 48). Embora desconsiderando a literatura como epifenômeno das condições socioeconômicas, discordava de que a evolução da arte se fizesse apenas em conformidade com suas leis imanentes.

Conforme Sánchez Vázquez, Mehring analisou a arte como fenômeno social pertencente à superestrutura e, enquanto tal, condicionada aos interesses de classes, "sem poder se elevar a um nível universalmente humano" (SÁNCHEZ VÁZQUEZ, 1978, p. 13).

Em meio aos teóricos marxistas que, do final do século XIX ao início do século XX, tentaram sistematizar o legado deixado por Marx e Engels, no que tange ao pensamento estético, Sánchez Vázquez destaca os postulados de Paul Lafargue (1842-1911), cujo empenho era destacar os vínculos entre arte e interesses sociais. Contudo, Lafargue "ao sublinhar o caráter ideológico da obra artística perde de vista seu modo específico de refletir a realidade" (SÁNCHEZ VÁZQUEZ, 1978, p. 13).

Nesse processo de resgate da herança de Marx e Engels, Sánchez Vázquez dá destaque às formulações de Lênin (1870-1924). Em Materialismo e empiriocriticismo (1909), Lênin não aborda a arte de forma específica, todavia pode-se depreender de sua análise que "como as demais formas ideológicas, a arte se acha historicamente 
condicionada, o que não exclui que as verdades que ela nos proporciona tenham certa validade objetiva” (SÁNCHEZ VÁZQUEZ, 1978, p. 16). Lênin defende que a arte deve ser concebida enquanto uma forma de reflexo da realidade. O que não se pode inferir de tal assertiva é que a teoria do reflexo do conhecimento científico proposta por Lênin pudesse ser diretamente transposta ao domínio da arte. "Na verdade, somente cabe falar do reflexo artístico quando a arte cumpre uma função cognoscitiva $[. .$.$] . Em suma, [...] o reflexo artístico difere radicalmente do$ científico" (SÁNCHEZ VÁZQUEZ, 1978, p. 16).

Konder ressalta que embora Lênin, chefiando o primeiro Estado proletário, visasse a obter da arte o apoio politico que fosse possivel, rejeitou a arte panfletária. Ademais, durante a década de 1920, houve, na União Soviética, uma grande efervescência artística, da qual se pode depreender a liberdade promovida pela política cultural leninista. Se esse fato não prova a eficácia politica de Lênin, certamente revela que "ela não atrapalhou a criação estética ou a promoção do amplo debate teórico" (KONDER, 1967, p. 62).

Konder apresenta, de um lado, uma intelligentsia vinculada ao anti-sociologismo, que, segundo ele, concentrava, em suas formulações, elementos idealistas; assim, nem sempre capaz de distinguir as devidas ligações entre arte e sociedade. Dessa vertente, destacam-se nomes como os de Mehring, Trotski, Eisenstein, Caudwell, Della Volpe e Kosik; e de outro, um grupo genericamente vinculado ao sociologismo, do qual sobressaem Plekhanov, Bukharin, Max Raphael, e ainda ideólogos mais comprometidos com o stalinismo, como Gorki e Zhdanov. Este último, cujas formulações representaram a expressão mais típica da linha estética que vigorou durante o governo de Stalin, reduziu a arte tão somente ao seu conteúdo ideológico, à sua eficácia enquanto instância de reflexão politicamente condicionada.

Essa postura reducionista, que vigorou durante o stalinismo, foi anunciada como uma defesa de princípios marxistas, quando na verdade, contrariava-os profundamente. Engels, em carta à jovem romancista Margaret Harkness, escrita em 1888, elucidou que as ideias 
expressas em uma obra sempre seriam prevalecentes sobre o posicionamento social do seu autor.

Ora, Balzac era politicamente um legitimista; a sua obra
grandiosa constitui uma elegia permanente da
decadência irreparável da boa sociedade; [...] [mas] os
únicos homens aos quais se refere com clara admiração
são os seus antagonistas politicos [...] verdadeiros
representantes das massas populares. O fato de Balzac
se ver compelido a agir contra as suas próprias simpatias
de classe preconceitos politicos, de ver a necessidade de
queda dos seus favoritos nobres e os descrever como
pessoas que não merecem melhor sorte [...] tudo isso
afigura-se-me um dos maiores triunfos do realismo e das
maiores características do velho Balzac (MARX; ENGELS,
1986, p. 71-72).

Engels reconhece que, mesmo simpatizante da monarquia, Balzac, independente disso, deixou figurar em seu romance uma visão realista da sociedade francesa, ou seja, o universo figurado na arte triunfou sobre a visão ideológica do autor. Assim, é possivel reconhecer que a "interferência subjetiva, a projeção dos valores e convicções pessoais do artista na obra, ao contrário, frustram a intenção realista e fazem a obra fracassar" (FREDERICO, 1997, p. 24).

Durante o $1^{\circ}$ Congresso dos Escritores Soviéticos, em 1934, nos termos estreitos propostos por Gorki, o realismo socialista foi conceituado "de maneira a atribuir maior importância ao termo socialista do que ao termo realismo" (KONDER, 1967, p. 87), implicando a redução do realismo à mera representação servil da realidade. A partir de então, o realismo socialista se tornou a marca artística oficial do Estado soviético, promovendo a passagem das expressões artísticas pluralistas às monolíticas, uma vez que a arte deveria interferir diretamente na reorganização política proposta pelo Partido Comunista. Desse modo, arbitrariamente, todas as produções artísticas foram submetidas a um ritmo disciplinar. Fato que, consequentemente, fez com que insurgissem fortes oposições à estética marxista, assimilada que foi, genericamente, a tais imposições. Conforme esclarece George Lukács, 
Durante o período stalinista, a teoria marxista - no que se refere aos pontos que são, sob este aspecto, decisivos se encontrava obscurecida e deformada, ao invés de se procurar uma solução efetiva no plano da concepção do mundo e no plano estético, preferiu-se, na maior parte das vezes, procurar refúgio [no] romantismo revolucionário (LUKÁCS, 1991, p. 185-186).

Os autores René Wellek e Austin Warren, por exemplo, declaram, indistintamente, que os críticos marxistas, além de estudarem as relações entre sociedade e literatura, definiam como tais relações deveriam ser "tanto na presente sociedade como em uma futura 'sem classes'. Eles praticam a crítica valorativa, 'judicial', baseada em critérios políticos e éticos, não literários" (WELLEK;WARREN, 2003, p. 114).

Tendo em vista tais generalizações, percebe-se a necessidade, em todos os aspectos, de esclarecer as diferenças entre a estética marxista ampla daquela prática cultural stalinista que vigorou sob a forte pressão do dogmatismo operante, na época. Assim, vale destacar que Lukács, em 1965, no prefácio acrescido posteriormente ao livro Marxismo e teoria da literatura, em relação aos artigos ali contidos, esclarece que

\begin{abstract}
O leitor de hoje deve levar em conta, naturalmente, que a forma de expressão destes artigos tinha de ser muito distinta daquela que eles teriam se fossem escritos hoje sobre os mesmos temas. Tal fato se manifesta não só nas imprescindiveis manobras táticas (citações de Stalin, etc.), como também, frequentemente, na estruturação de conteúdo. [...] Sem dúvida, já então, percebiamos corretamente as consequências perigosas da vulgarização burocrática e do enrijecimento da teoria marxista da literatura [...] O fato de que os métodos de Stálin constituíssem o centro deste estado de coisas só mais tarde se fez claro para nós. Não obstante, isto só influi no tom dos artigos. No que diz respeito à essência, ao contrário, continuo acreditando que, já naquela época, eu compreendera corretamente determinados problemas básicos (LUKÁCS, 1968b, p. 2).
\end{abstract}

O realismo soviético, certamente, verberou a visão marxista acerca da criação artística, mas, na prática, o sectarismo imposto à arte por meio dele não invalidou o alcance da autêntica crítica marxista. Nesse âmbito, Konder destaca, dentre outros, três motivos específicos 
que podem explicar as posições controvertidas em relação à estética marxista: primeiro, o fato de a filosofia marxista não constituir um sistema fechado de ideias definitivas; segundo, a ausência de uma sistematização por parte de Marx e Engels acerca de uma teoria estética; e, finalmente, um atraso na divulgação de alguns textos de Marx e Engels destinados "a uma apreciação circunstancial de questões estéticas [...] [que] não foram devidamente valorizados em suas indicações mais profundas" (KONDER, 1967, p. 2).

De acordo com essa observação, torna-se possivel deduzir que as questões particulares da estética tenham passado também por intrincados trajetos, mormente quando se coloca, na base da sua ontogênese, o condicionamento destas aos fatores socioeconômicos. Konder esclarece, nesse sentido, casos de desprezo absoluto pela causa estética por parte de alguns marxistas, como a experiência do economista marxista italiano Antonio Labriola (1873-1959) que escreveu uma carta a Benedetto Croce (1866-1952) declarando-se compungido por saber que este se dedicava a um tratado sobre a arte.

Não obstante essas limitações e outras que esquematizaram a pesquisa literária dentro dos moldes do sociologismo e do sectarismo stalinista, Giovanni Ricciardi enfatiza que coube à tradição marxista "o mérito de ter contribuído de maneira determinante para uma mais orgânica e madura definição dos nexos que enquadram as manifestações estéticas nas condições da sociedade" (RICCIARDI, 1971, p. 26).

\section{As acepções lukacsianas e seu influxo na critica marxista}

Carlos Nelson Coutinho confere destaque, nesse contexto, ao sistema teórico de Georg Lukács como um "tertium datur dialético entre revisionismos e dogmatismos" (COUTINHO, 1967, p. 96). Para Coutinho, as divergências no interior da critica marxista partem, principalmente, dos clivados posicionamentos em torno da categoria do 
realismo, constituindo dissensões de natureza metodológica e filosófica consubstanciadas pela ausência de uma visão integrada entre materialismo dialético e materialismo histórico. Para ele, houve um desvio que se configurou em reduzir o marxismo a um materialismo histórico relativista, que reduz a obra de arte à sua gênese social. Sem a integração entre o materialismo histórico e o materialismo dialético, não se pode entender a obra de arte de acordo com o sistema de leis que the é próprio e enquanto fenômeno que transcende o contexto históricosocial do qual foi engendrado. Tal integração, conforme Coutinho, promove a ruptura de uma visão mecanicista e unilateral. Tal reclamação, para ele, atravessa o esquema teórico elaborado por Lukács, conforme se pode perceber no pensamento exposto abaixo:

\begin{abstract}
Pensadores inclinados ao materialismo mecanicista sublinharam - corretamente - a identidade do mundo refletido pela ciência e pela arte, mas em maior ou menor medida negligenciaram a especificidade do reflexo artístico. [...]. Tão somente o materialismo dialético pode colocar concreta e adequadamente o problema do conteúdo artisticamente elaborado, sobre a base da peculiaridade do reflexo estético, possibilitando assim a justa compreensão da relação entre conteúdo e forma na estética (LUKÁCS, 1968a, p. 270-271).
\end{abstract}

Na esteira do marxismo-leninismo - como destaca Coutinho -, Lukács considerou a arte como um modo peculiar de manifestação do reflexo da realidade, negando-a enquanto expressão de uma psicologia de classe ou biografismo. Ao contrário do que muitos pesquisadores, apressadamente, afirmam, Lukács defendeu que não há na forma romanesca um reflexo de modo direto e empírico do real. O que é legítimo no sistema lukacsiano é que somente a partir do realismo, categoria central da crítica marxista, pode-se aferir se uma obra realiza, de fato, um autêntico reflexo do real, respeitando as leis específicas do conhecimento artístico do mundo.

A obra realista, penetrando além da face reificada do real, reconstitui sua totalidade com as contradições que lhe são próprias, de modo a alcançar o essencial no plano peculiar dos problemas humanos 
particulares nela abordados. E, para tal, o processo deve envolver o todo das relações sociais em uma riqueza de conteúdo e forma. Dada essa peculiaridade, Lukács se porta desfavoravelmente em relação tanto à arte naturalista ${ }^{3}$ - pelo predomínio da representação fotográfica da realidade - quanto à arte de vanguarda, ou por falsear a forma, no caso do expressionismo, ou por subestimar o conteúdo, no caso do formalismo. Segundo Lukács, na arte de vanguarda,

encontramos, naturalmente, esta espécie de dissolução do real como base da associação de ideias [...]. Ela acentua-se fortemente quando os individuos que monologam passam a ser os únicos suportes da "realidade" representada; e esta tendência é levada ao cúmulo quando esses indivíduos aparecem como idiotas ou semi-idiotas, cujas representações confusas, incessantes, sem ligação, são o único meio de comunicação entre o leitor e o "universo" do escritor. [...] Portanto a dissolução do homem e dissolução do mundo pertencem ambas ao mesmo sistema, ampliam-se e reforçam-se mutuamente. Na base, encontramos sempre a mesma concepção do homem: um ser desprovido de qualquer unidade objetiva, simples sequência incoerente de fragmentos instantâneos, extraídos de experiências vividas que são, por definição, tão impenetráveis para o individuo que as vive como para os outros homens (LUKÁCS, 1991, p. 46).

Toda a hostilidade lukacsiana em relação à arte de vanguarda ${ }^{4}$ tem como base a defesa de que as causas sociais do comportamento humano não podiam ser substituídas por psicologismos, cabendo ao romance fazer o resgate da totalidade perdida. Os vanguardistas foram criticados por criarem um abismo entre o indivíduo e o mundo exterior: “o indivíduo é sempre uma realidade psicológica imediata e o mundo

3 "[...] o naturalismo despoetiza o real, reduz a uma prosa vulgar a imagem que dele apresenta; o seu parti pris de esquematização torna-o cego, com efeito, [...] para a própria riqueza do real, [...] fica reduzido a castrar, a banalizar os traços particulares em que se revela a ação de leis profundas e secretas" (LUKÁCS, 1991, p. 185).

${ }^{4}$ Convém elucidar que Lukács (1991, p. 133), em Realismo crítico hoje, concebe a obra kafkiana como uma expressão decadente, embora artisticamente interessante. Ademais, reconhece Kafka como um escritor realista, cuja expressão revela um realismo de tendência meramente alegórica, por não haver figuração da realidade concreta. Posteriormente, mesmo sem um tratado sistemático sobre o assunto, Lukács formulou uma crítica sobre Kafka, cujo conteúdo veio a alterar, positivamente, os anunciados feitos anteriormente, em 1957 (COUTINHO, 2005b, p. 26). 
um caos desordenado e incompreensivel" (FREDERICO, 1997, p. 42).

Tal forma de defesa do realismo não passou incólume diante de outros pesquisadores marxistas que julgaram as acepções lukacsianas fechadas às mudanças que, processadas no contexto social, repercutiriam, inelutavelmente, na forma romanesca. O dramaturgo alemão Bertolt Brecht (1898-1955), embora concordasse com Lukács no tocante à literatura como elemento ativo na transformação do processo histórico, retorquiu à eleição do romance realista do século XIX como o locus, por excelência, de manifestação do realismo. Sendo dialético, o processo social suscitaria novas expressões que, irremissivelmente, alargariam o modo de atuação do escritor realista.

Para Brecht, a teoria lukacsiana focalizava apenas uma forma específica de romance - a produção realista do século XIX - e, contrariamente a tal postura, defendeu as novas formas estéticas como uma resposta aos conflitos engendrados pela sociedade contemporânea. Assim, o realismo acompanharia o processo histórico no seu dinamismo. "A isto Brecht chamou de 'riqueza e amplitude do estilo realista'; e sempre repudiou que as convenções artísticas fizessem da arte algo convencional" (POSADA, 1970, p. 21).

Lucien Goldmann (1913-1970) concordou com o húngaro acerca da concepção do romance enquanto protesto de força humanista contra o processo de reificação, todavia não o concebeu como reflexo da realidade, pois o considerava uma concretização da visão de mundo da classe a que pertence o autor. "Semelhante estrutura [romance] só poderia ser elaborada por um grupo, podendo o indivíduo imprimir-lhe apenas um grau de coerência” (GOLDMANN, 1990, p. 19).

Tal como Brecht, Goldmann sustenta que as formas literárias se modificam. Portanto, vê o Nouveau Roman e uma parcela da produção vanguardista como forças de resistência contra a reificação da vida social; ao contrário de Lukács, que identificava na vanguarda a decadência da burguesia; defendendo que apenas a arte realista, na qual se processa dialeticamente a relação entre o singular e o universal, poderia sobreviver ao seu tempo, tanto pela profundidade quanto pelo 
elevado nível estético.

O poeta austríaco e filósofo de formação marxista Ernest Fischer, no ensaio $A$ necessidade da arte, de 1959, embora concordando com Lukács no que tange à missão desalienante da arte, torna-se cauteloso quanto a sua teoria acerca do realismo.

Parece mais útil, mais prático, por conseguinte, confinar o conceito de realismo na arte à acepção de um método particular, tomando o maior cuidado - e nós não o esqueceremos - para não converter tal definição em um julgamento qualitativo. [...] O realismo - em seu sentido mais estrito - é apenas uma das possiveis formas de expressão, e não a única (FISCHER, 1979, p. 123-124).

A rigidez lukacsiana em relação ao realismo clássico é também questionada por Adolfo Sánchez Vázquez. Como todos os intelectuais marxistas atuantes, Sánchez Vásquez - após as severas denúncias feitas ao aparato stalinista por Nikita Khrushchev, em 1956, durante o XX Congresso do PCUS (Partido Comunista da União Soviética) retornou ao manancial de Marx e Engels, como também o fez Lukács, e promoveu, a partir daí, um redirecionamento em suas pesquisas.

Ao definir sua perspectiva diante da reflexão estética, Sánchez Vázquez - não obstante elucide a grande relevância do pensamento de Georg Lukács ao investigar a função cognitiva da arte, bem como admita que sua teoria sobre o realismo não exclui, cabalmente, todos os romances de vanguarda - reconhece na teoria do húngaro um tom normativo. Sánchez Vázquez sublinha que não há uma absoluta incomunicabilidade entre o realismo e a arte de vanguarda, já que as inovações formais vanguardistas são impulsionadas "pelas modificações de conteúdo, ditadas pelas transformações da própria realidade humana" (SÁNCHEZ VÁZQUEZ, 1978, p. 40).

Nesse âmbito, cabe inserir, aqui, as pesquisas de um dos mais influentes britânicos do pensamento de esquerda, Raymond Williams (1921-1988) que, juntamente com Thompson e Hoggart, esteve à frente dos chamados Cultural Studies. Foi por meio da sua adesão à New Left, que Williams se inteirou do debate promovido pelos expoentes da 
intelligentsia marxista ocidental. Segundo esclarece Maria Elisa Cevasco (2001, p. 146), mesmo reconhecendo significativo avanço empreendido pela teoria do reflexo (de Georg Lukács), pela teoria da homologia (de Lucien Goldmann) e pela teoria da mediação (de Theodor Adorno), Raymond Williams denunciou o caráter interpretativamente dualista da arte demarcado por tais teorias. Estas partem do pressuposto de uma base socioeconômica determinante e de uma superestrutura cultural determinada5; aspecto que, camuflando a inter-relação entre ambas, torna-se um empecilho para a percepção da arte enquanto elemento material que, dialeticamente, é produto e produção da realidade histórico-social.

Reflexo, homologia ou mediação impediriam o fundamental: ver que "a arte é também material, na medida em que é uma atividade que se desenvolve sobre algo que é material, seguindo formas e convenções que são históricas e sociais" (CEVASCO, 2001, p. 146). Williams questiona o fato de que, por meio da teoria do reflexo, uma arte seja concebida como ideologia e não como arte, caso ela não esteja dentro dos parâmetros da "grande arte realista". O crítico esclarece que se o reflexo artístico

Não o for [realista] (e a prova pode ser feita pela
comparação desse conhecimento dado da realidade com
qualquer arte real produzida), então é um caso de
deformação, falsificação ou superficialidade: não arte,
mas ideologia. Foram então possíveis ampliações
precipitadas para novas distinções categóricas: não arte
progressista, mas arte reacionária; não arte socialista,
mas arte burguesa ou capitalista (WILLIAMS, 1979, p.
100).

No entanto, no que diz respeito ao estudo da reificação e da totalidade desenvolvido por Lukács, Williams reconhece tratar-se de

5 Para Williams, a base - na visão daqueles que defendem infra-estrutura e superestrutura como entidades concretas separáveis - é quase concebida como um objeto de propriedades uniformes, quando ela, na verdade, "é em si mesma um processo dinâmico e internamente contraditório" (WILLIAMS, 1979, p. 86). Ele defende a cultura enquanto "produto e produção de um modo de vida determinado, e não como reflexo de uma base econômica" (CEVASCO, 2001, p. 138), monolítica e imutável. 
uma evolução. Para ele, a ideia da totalidade representava uma arma crítica contra a reificação e contra o próprio capitalismo. Considerando que, na teoria lukacsiana, a realidade refletida não era concebida de forma estática, a "descrição da realidade social como um processo dinâmico é, então, um grande avanço, mas restringido, e de certo modo anulado, pela referência familiar e pressaga a 'leis"' (WILLIAMS, 1979, p. 105).

A restrição de William, pois, faz-se em função das leis básicas que regeriam a realidade, ou seja, a base como determinante do movimento social. A reflexão da base nas obras de arte torna-se um "standard de julgamento. Assim, o que já é conhecido como realidade da 'base', do processo sócio-histórico material, é refletido com maior ou menor sucesso pela arte" (CEVASCO, 2001, p. 139).

Nesse debate, convém destacar o posicionamento de Fredric Jameson. Em Marxismo e forma (1971), ele ressalta a legitimação da vertente dialética no contexto contemporâneo e retoma a teoria de grandes expoentes da tradição marxista como Bloch, Lukács, Sartre, além de frankfurtianos. Nessa incursão, demonstra no capítulo intitulado Em defesa de Georg Lukács a singularidade das categorias desenvolvidas pelo pensador húngaro na constituição da matriz intelectual marxista.

Para Jameson, o projeto lukacsiano deve ser analisado a partir dos diversos períodos da sua vida: neokantiano, hegeliano, bolchevista e finalmente, nos anos de 1960, o Lukács da Estética6: tratado que, de certa forma, retoma o neokantismo da primeira fase. Ao contrário de autotraições, esses sucessivos posicionamentos revelam uma reflexão continua sobre a literatura, sua estrutura e sua relação com a realidade que expressa.

\footnotetext{
6 Obra lançada em 1963, correspondendo "à primeira das três partes que deveriam compor o projeto original. Mesmo que inconclusa, Lukács considerava a parte que publicou ainda em vida, pelas abordagens nela contidas, plenamente compreensivel sem as outras duas que acabou não concluindo. A dimensão da obra impressiona. Sua edição espanhola, a 'Estética 1 - La peculiaridad de lo estético' (1982), contém quase duas mil páginas distribuídas ao longo de dezesseis capítulos e quatro volumes" (DUAYER, 1999).
} 
Jameson destaca que, após a obra História e consciência de classe, já não era possível a Lukács retornar à tipologia do romance (romances do idealismo abstrato e romances da desilusão romântica) proposta em A teoria do romance. Superada essa modalidade hegeliana de dedução tipológica, Lukács explorará as obras capazes de refletir a realidade social a partir de sua concreta historicidade. Se mais tarde ele abandona a descrição e passa à prescrição, atacando escritores modernos, para Jameson, não invalida o ponto de partida da pesquisa do autor. Lukács - abandonando a visão de desilusão subjacente ao romance enquanto expressão simbólica da ruptura entre a subjetividade e o sentido, própria do mundo moderno - repudiou a simbolização e se dedicou ao realismo de Scott, Balzac e Tolstói, concebendo no gênero romanesco a capacidade de conferir certo significado à vida.

Jameson analisa a crítica que Lukács faz à arte vanguardista como um processo natural à metodologia adotada ao longo de todo o seu projeto crítico. Trata-se de uma postura já implícita no ensaio $A$ teoria do romance, de 1916, quando o jovem Lukács salta da forma metafísica às relações em termos históricos, até a produção do Lukács marxista, como em O realismo crítico hoje, de 1958. De acordo com Jameson, para o teórico húngaro, que sempre defendeu a primazia da narração sobre a descrição, não é ocasional sua ostensiva resistência ao abandono do enredo e à renúncia da narrativa realista, aspecto característico das obras de vanguarda. Sobre esse posicionamento de Lukács, Jameson esclarece que

a vantagem de Lukács sobre os teóricos simpatizantes do moderno está na sua modalidade de pensamento, diferenciadora e profundamente comparativa. Ele não se instala no interior do fenômeno moderno, completamente entregue a seus valores fundamentais e capaz apenas de observá-lo a partir da sua própria ótica. Ele pode defini-lo e marcar seus limites, como momento histórico, frente ao que ele não é. No entanto, tais comparações parecem implicar, na sua própria estrutura, um julgamento a favor do termo mais antigo (JAMESON, 1985, p. 155). 
Nelson Coutinho, no ensaio Lukács, Proust e Kafka (2005), reconhece que Lukács tentou rever alguns posicionamentos acerca do realismo: em 1965, Lukács acrescentou um prefácio a uma coletânea de ensaios escritos na década de $1930^{7}$, admitindo que o realismo crítico é também compativel com o uso de certas técnicas vanguardistas; em 1963, em uma edição para o inglês de Realismo crítico hoje, Lukács incluiu os escritores norte-americanos como Thomas Wolfe e Eugene O’Neill, além da italiana Elsa Morante e do dramaturgo alemão Bertolt Brecht como expressões do realismo, em uma atitude que demonstra uma ampliação no conceito tradicional de realismo e, em 1969, no ensaio Solschenitzyn - dedicado aos primeiros romances do homônimo autor russo: O primeiro círculo e $O$ pavilhão dos cancerosos - Lukács estruturou um trabalho mais orgânico de revisão, indicando o modo pelo qual as novas bases sociais e ideológicas do capitalismo tardio ocasionaram uma modificação formal na estrutura romanesca.

A postura de autocrítica marcou a trajetória teórica de Lukács, tornando-a mais ampla. Não foi aleatoriamente que ele se tornou uma referência de irrefutável importância no estudo da relação entre arte e sociedade, de tal modo que as divergências de outros críticos surgidas a partir dos seus postulados representam expedientes imprescindiveis à atualização das categorias teóricas da crítica marxista como um todo.

Nesse sentido, vale lembrar as pesquisas, no campo da arte, realizadas pelo próprio Fredric Jameson. Constituindo um marco no mainstream da crítica marxista, a apreensão do princípio totalizante exige, certamente, novos métodos para atender à demanda dos tempos atuais. Nesse sentido, vale destacar o sistema teórico proposto por esse crítico norte-americano, sempre preocupado em responder os problemas suscitados pelo seu tempo: "não podemos, no entanto, voltar a práticas estéticas elaboradas com base em situações históricas e dilemas que não são mais os nossos" (JAMESON, 2004, p. 76). Segundo ele, no atual estágio do capitalismo, a arte perdeu sua autonomia

7 Reunidos no volume Marxismo e teoria da literatura, lançado no Brasil, em 1968, pela editora Civilização Brasileira. 
relativa, integrando-se à produção de mercadorias; por conseguinte, sua proposta teórica jamais poderia prescindir dessa variação no domínio cultural que "inclui uma modificação significativa de sua função social" (JAMESON, 2004, p. 74). O trabalho crítico atual exige, para fim de uma eficácia interpretativa da arte, novos códigos capazes de apreender sua especificidade no âmbito da dinamicidade histórica.

Apontando para a especificidade da arte no espaço pós-moderno, Jameson argumenta que houve uma explosão da cultura por todo o domínio social e, desde as questões econômicas até a própria estrutura da psique, tudo passou a "ser considerado como cultural, em um sentido original que não foi até agora teorizado" (JAMESON, 2004, p. 74). A intersecção da esfera cultural com a econômica eclipsa, conforme observa o crítico, a distinção entre base e superestrutura, em uma dimensão sem precedentes e o fetichismo da mercadoria estampado na produção cultural esvazia o caráter utópico da arte pós-moderna. Assim sendo, Jameson defende que deve ser retomada a função educativa da arte, dada a dimensão conscientizadora da qual ela não pode prescindir, justificando:

O modelo cultural que proponho, do mesmo modo, coloca em evidência as dimensões cognitivas e pedagógicas da arte e da cultura politicas, dimensões que foram enfatizadas de modos bem diferentes por Lukács e Brecht (para os diferentes momentos do realismo $\mathrm{e}$ do modernismo, respectivamente) (JAMESON, 2004, p. 76).

Reconhecendo que o indivíduo está impelido para uma completa desorientação no que tange ao seu posicionamento no sistema social e econômico, Jameson prima por um projeto avesso às correntes que proliferam a fragmentação, defendendo uma metodologia oposta a dos filósofos pós-estruturalistas que revogam as totalizações em nome da diferença e da dispersão. No reverso de tais posturas, argumenta o crítico:

Para que essas percepções sejam celebradas em sua intensidade, devem ser acompanhadas por uma aparência inicial de continuidade, de uma ideologia de unificação já consagrada, que elas devem rejeitar e 
destruir. Por exemplo, o valor do molecular em Deleuze depende estruturalmente do impulso molar ou unificador preexistente em função do qual sua verdade é lida. Portanto, vamos sugerir que se trata de filosofias de segundo grau ou criticas que reconfirmam o status do conceito de totalidade por meio de sua reação contra ele (JAMESON, 1992, p. 48-49).

A teoria totalizante jamesoniana ultrapassa a trincheira da imediaticidade do real. Se de um lado, a realidade está correspondendo a um vislumbre de fragmentos desconexamente percebidos - "uma visão do presente como pura heterogeneidade, como diferença aleatória" (JAMESON, 2004, p. 31) - a estética do mapeamento cognitivo revelase, do outro, como um exercício que busca totalizar, imprescindivel para uma práxis politica consciente. É, pois, um procedimento que se lança como um desafio ao estado de desorientação do indivíduo no atual momento histórico, em cuja ordem operam desmedidos efeitos alienantes.

Associando ao exercício do mapeamento cognitivo a função pedagógica da arte, Jameson alude ao teatro épico de Brecht como uma forma de evidenciar a relação complexa e necessária entre arte e pedagogia. A referência feita a Lukács e a Brecht corrobora o imperativo de que, para Jameson, tanto a arte como as teorias que dela se ocupam não podem preterir o caráter político. Retomá-lo é o pressuposto básico do exercício do mapeamento cognitivo, que é tanto uma estratégia voltada para a consciência de classe quanto se faz uma política cultural genuinamente conscientizadora e imprescindivel aos tempos atuais.

\section{Referências bibliográficas}

CANDIDO, Antonio. Literatura e sociedade: estudos de teoria e história literária. São Paulo: T. A. Queiroz, 2000.

CEVASCO, Maria Elisa. Para ler Raymond Williams. São Paulo: Paz e Terra, 2001. 
COUTINHO, Carlos Nelson. Cultura e sociedade no Brasil: ensaios sobre ideias e formas. Rio de Janeiro: DP\&A, 2005a.

- Literatura e humanismo: ensaios de crítica marxista. Rio de Janeiro: Paz e Terra, 1967.

. Lukács, Proust e Kafka: literatura e sociedade no século XX. Rio de Janeiro: Civilização brasileira, 2005b.

DENIS, Benoît. Literatura e engajamento: de Pascal a Sartre. São Paulo: EDUSC, 2002.

DUAYER, Juarez Torres. Lukács e a estética marxista: sintese, esboço ou tentativa? 1999. Disponivel em: < http://www.unicamp.br/cemarx/juarez.htm>. Acesso em: 2 jun. 2011.

ESCARPIT, Robert. Sociologia da literatura. Lisboa: Arcádia, 1969.

FISCHER, Ernst. A necessidade da arte. Rio de Janeiro: Zahar, 1979.

FREDERICO, Celso. Lukács: um clássico do século XX. São Paulo: Moderna, 1997.

GOLDMANN, Lucien. A sociologia do romance. Rio de Janeiro: Paz e Terra, 1990.

JAMESON, Fredric. Marxismo e forma: teorias dialéticas da literatura no século XX. São Paulo: Hucitec, 1985.

- O inconsciente politico: a narrativa como ato socialmente simbólico. São Paulo: Ática, 1992.

- Pós-modernismo: a lógica cultural do capitalismo tardio. São Paulo: Ática, 2004.

KONDER, Leandro. Os marxistas e a arte: breve estudo histórico-crítico de algumas tendências da estética marxista. Rio de Janeiro: 
Civilização Brasileira, 1967.

LUKÁCS, Georg. Introdução a uma estética marxista: sobre a categoria da particularidade. Rio de Janeiro: Civilização Brasileira, 1968a.

- Marxismo e teoria da literatura. Rio de Janeiro: Civilização Brasileira, 1968b.

- Realismo crítico hoje. Brasília: Thesaurus, 1991.

MARX, Karl; ENGELS, Friedrich. Sobre literatura e arte: Marx-Engels. São Paulo: Global, 1986.

POSADA, Francisco. Lukács, Brecht e a situação atual do realismo socialista. Rio de Janeiro: Civilização Brasileira, 1970.

RICCIARDI, Giovanni. Sociologia da literatura. Lisboa: Publicações Europa-América, 1971.

SÁNCHEZ VÁZQUEZ, Adolfo. As ideias estéticas de Marx. Rio de Janeiro: Paz e Terra, 1978.

WILLIAMS, Raymond. Marxismo e literatura. Rio de Janeiro: Zahar, 1979.

WELLEK, René; WARREN, Austin. Teoria da literatura e metodologia dos estudos literários. São Paulo: Martins Fontes, 2003. 